\title{
Promoting knowledge of statins in patients with low health literacy using an audio booklet
}

\author{
This article was published in the following Dove Press journal: \\ Patient Preference and Adherence \\ 9 August 20II \\ Number of times this article has been viewed
}

\author{
J Travis Gossey' \\ Simon NWhitney ${ }^{2}$ \\ Michael A Crouch ${ }^{3}$ \\ Maria L Jibaja-Weiss ${ }^{2}$ \\ Hong Zhang ${ }^{4}$ \\ Robert J Volk ${ }^{4}$ \\ 'Department of Medicine, Weill \\ Cornell Medical College, New York, \\ NY, USA; ${ }^{2}$ Department of Family \\ and Community Medicine, Baylor \\ College of Medicine, Houston, TX, \\ USA; ${ }^{3}$ Memorial Family Medicine \\ Residency Program, Sugar Land, TX, \\ USA; ${ }^{4}$ Department of General Internal \\ Medicine, The University of Texas \\ MD Anderson Cancer Center, and \\ Houston Center for Education and \\ Research on Therapeutics, Houston, \\ TX, USA
}

Background: Statins are generally well tolerated and effective at reducing a patient's risk of both primary and secondary cardiovascular events. Many patients who would benefit from statin therapy either do not adhere to or stop taking their statin medication within the first year. We developed an audio booklet targeted to low health literacy patients to teach them about the benefits and risks of statins to help the patients adhere to their statin therapy.

Methods: Through focus groups and an iterative design, an audio booklet was developed for both English-speaking and Spanish-speaking patients. We then compared the booklet with standard of care in 132 patients from our target patient population to measure its impact on knowledge and understanding of statins.

Results: The patients enjoyed the audio booklet and showed significant increases in knowledge after listening to it when compared with those who received the standard of care materials.

Conclusion: The audio booklet shows promise as a tool that can be used effectively in clinical practice to teach patients about statin therapy.

Keywords: patient adherence, patient education, medical decision-making, hypercholesterolemia

\section{Introduction}

Coronary heart disease continues to be the leading cause of death in the US. HMG-CoA reductase inhibitors (statins) reduce the risk of heart attack and stroke by $30 \%-40 \%{ }^{1}$ Statin therapy has shown a very low incidence of harm. ${ }^{2}$ Despite their demonstrated efficacy and safety, the acceptance, persistence, and adherence rates with statins are below 50\%..$^{3-9}$ Many patients who start taking medication to lower cholesterol and reduce their risk for heart attack and coronary death, stop taking it; and 30\%-50\% of patients take self-initiated "drug holidays." ${ }^{10}$ A majority of patients who start statin therapy stop it within the first year. ${ }^{11}$ A vast amount of literature exists on improving adherence to chronic medication, but interventions to improve adherence to chronic medications have seldom produced impressive results. ${ }^{12-14}$ Therefore, more effective interventions are needed. As the increased disease burden and the economics surrounding lack of adherence to statin medications becomes better understood, the need for these interventions become more acute.

To varying degrees, dyslipidemia affects every patient population. One of the more difficult populations to educate about statin therapy is the low health literacy patient population. Health literacy is defined by the Institute of Medicine as the degree to which individuals have the capacity to obtain, process, and understand basic health information and services needed to make appropriate health decisions. ${ }^{15}$ Individuals with low
Department of Medicine, Weill Cornell Medical College, 575 Lexington Ave, Third Floor, New York, NY I002I, USA

Tel +l $212746047 \mid$

Fax +l 6469620454

Email jtg9003@med.cornell.edu 
health literacy have poorer health outcomes and are more likely to be poor, medically underserved, and/or of minority ethnicity. ${ }^{16-18}$ These issues are even more pronounced for immigrants. In our patient population, over half the patients only speak Spanish.

Given that many of the patients in this vulnerable population have poor reading skills and difficulty understanding health-related information, we developed an educational audio booklet that addresses the most common questions and concerns that patients have about taking statin medications to reduce their risk for cardiovascular events. The audio booklet is not a patient decision aid, rather it is targeted to patients who have been prescribed statin medications and is meant to address their questions and concerns about taking statin therapy. We intentionally designed the intervention for patients with poor to no reading skills. The purpose of this study was to determine the feasibility of the use of an audio booklet in a community health clinical setting with patients from the target patient population. The program was developed both in English and Spanish to address the needs of the target population.

\section{Methods}

\section{Theoretical framework}

The Extended Parallel Process Model (EPPM) served as the framework for developing the health messages in the audio booklet intervention. While drawing concepts from fear appeal theories, the EPPM presents a broader view of responses to health messages as being both positive and negative. ${ }^{19}$ Health messages are seen as involving two cognitive components, ie, an appraisal of threat and an appraisal of efficacy related to the recommended response or behavior. The threat appraisal involves perceptions of personal susceptibility to the threat (ie, "it can happen to me") and perceived severity (ie, "it is a serious concern"). People who have low perceived susceptibility or severity will likely ignore the health message. Perceived efficacy appraisal is characterized by perceptions of self-efficacy (ie, "I can engage in the recommended behavior") and response efficacy (ie, "if I engage in the recommended behavior, it will benefit me"). People who perceive low selfefficacy and response efficacy are likely to develop a defensive motivation and reject the message. This describes the fear control process. People who perceive high self-efficacy and response efficacy develop a protective motivation and accept the message. This describes the danger control process in the EPPM. $^{19}$

The EPPM has direct implications for the design of health messages, including messages about statin medications.
Patients with hyperlipidemia who have been prescribed a statin medication need to understand that they are at increased risk of heart attack and stroke and that these are serious concerns. Furthermore, they need to learn about taking the medication and its potential harms, and that by taking the medication they can lower their risk.

\section{Development of the intervention}

For baseline knowledge, structured interviews were conducted with patients from the target patient population in the Harris County Hospital District. After formal review and approval by the institutional review board, patients were recruited using fliers in the target clinics. Eighteen interviews were conducted (nine Hispanic patients [six Spanish speakers] and nine non-Hispanic English speakers) with patients taking statin medications to explore their beliefs, expectations, and attitudes about treating high cholesterol and statins in particular. Eligible patients were 35-75 years of age. The research team coded the interviews by using the standard methodologies in Atlas.ti software (Berlin, Germany). Based upon the data, an audio booklet design format was selected because patients indicated that it is a favorable way to receive information. Additionally the format combines visual components (bulleted text, graphics, and engaging illustrations) with accompanying narration to aid patients with poor reading skills and limited ability to understand health-related information.

The flow of the program contains five distinct audio-only components. In the first component, a community physician describes the basic factual information about cholesterol, where it comes from, and how it can affect a person's health. Next a testimonial describes why a person who has high cholesterol, but who has not had any cerebrovascular events, decided to take statins, and how they handled a potential adverse reaction to them. Next, the community physician returns to discuss statin medications, their role in prevention, and reasons why a patient may want to take a medication even if they do not feel any different before or after taking them. A pictograph is used to provide a visual representation of the incremental benefit of taking a statin on reducing heart attack and stroke. Following that, another testimonial is presented about a patient with a previous cardiovascular event and appropriate for secondary prevention, where she relates her story as to why she takes the medication. Pictures of the persons giving the testimonials appear in the audio booklet. The reading level using the Flesch-Kincaid method was third grade and had a Flesch Reading Ease score of 81. The audio booklet concludes with a discussion of the potential side effects of statins, including warning messages about serious complications, 
and how to manage them. The English language version of the narration was 10 minutes in length, and the Spanish version was 11 minutes in length. A printed booklet accompanies the audio program to provide visual reinforcement of the audio and only contains the highlights (ie, bulleted text) of the audio. Additionally, the Spanish translation was back translated to English to make sure the message was consistent (see Figure 1 for sample pages from the audio booklet).

\section{Subjects and setting}

Eligible subjects were primary care patients who had been told by their primary care provider that they had high cholesterol and were prescribed a statin medication or had any prescription refilled within the past three months, 35-75 years of age, and English or Spanish speakers. Patients were excluded if they were blind, did not speak English or Spanish, were too ill to participate, or if they refused to enter the study. Subjects were recruited from patients presenting for care at community health centers operated by the Harris County Hospital District. The Baylor College of Medicine institutional review board and the Harris County Hospital District research office approved the project to be undertaken in human subjects.

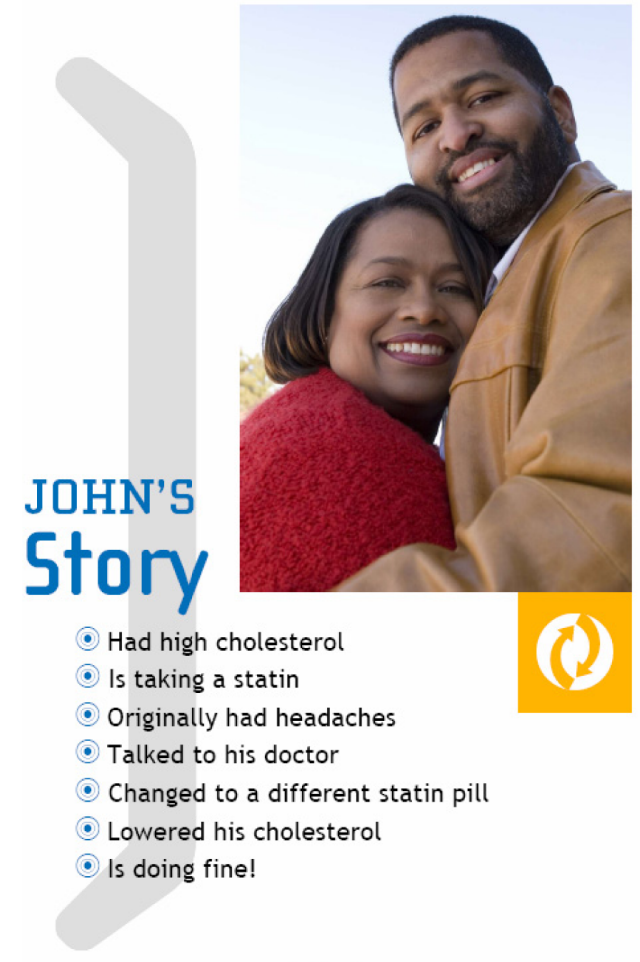

Figure I Sample pages from the audio booklet. Note: Photograph (C) iStockphoto.com.

\section{Procedures}

Patients with scheduled appointments were prescreened through electronic medical records for eligibility, and then approached by study personnel at the time the patient presented at the clinical center. For interested patients, eligibility was reassessed by patient self-report and they then were consented to participate in the study. A randomization block design was used to allocate patients to intervention and control groups, and accrual continued until 66 African American and 66 Hispanic patients had been randomized. Research staff were blinded to the patient's assigned group until the envelope containing the randomization sequence was opened after obtaining informed consent and prior to completing the demographic questions.

Each patient completed the Short Test of Functional Health Literacy in Adults ${ }^{20}$ before beginning the interviews. The study measures were administered via interview and collected at the study clinical sites. The preintervention interview included demographic questions, a knowledge measure, and a measure of EPPM constructs. Patients assigned to the intervention arm then completed the audio booklet; control group patients received the HCHD standard patient educational brochure on cholesterol and statin medications. The postintervention interview included the
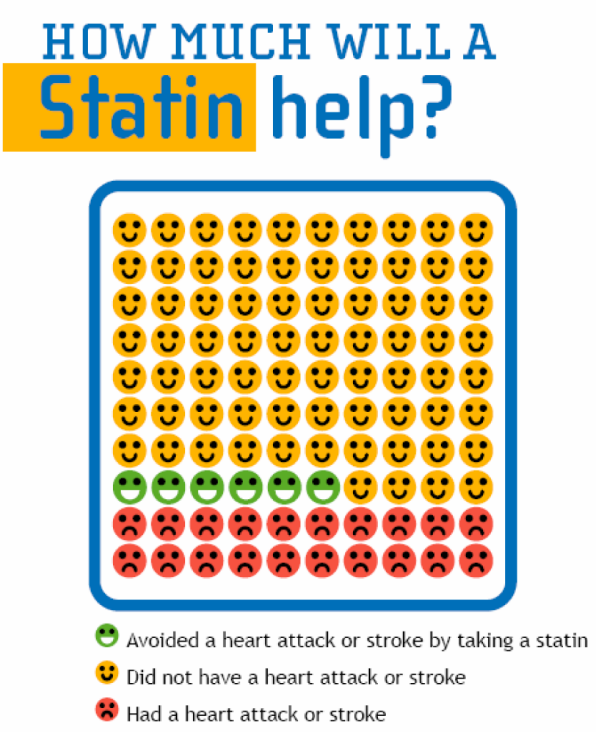

\section{For every 100 people taking a statin}

(c) Six people missed having a heart attack or stroke by taking a statin every day.

(C) If you already had a heart attack or stroke, then your benefits from a statin are even better! 
knowledge measure, and EPPM indicators. The audio booklet patients were asked questions about acceptability of the device immediately after completing the postintervention interview.

\section{Measures}

Cholesterol and statin medication knowledge was assessed using a 15-item measure developed for this study to reflect the factual information included in the audio booklet and the standard material already used in the clinic. The items were written as statements with "true," "false," or "don't know" response options. The Risk Behavioral Diagnosis Scale was used to measure four key concepts from the EPPM, ie, response efficacy, self-efficacy, susceptibility, and severity. ${ }^{19}$ The Risk Behavioral Diagnosis Scale has demonstrated adequate internal consistency, reliability (alpha coefficients $>0.70$ ), and confirmatory factor analysis supports the four-dimension structure of the measure reflecting the key concepts from the EPPM. ${ }^{19}$ The 12 -item measure was adapted for statin medication to prevent heart attack and stroke, as is recommended by the developer. The measure uses a seven-point scale, ranging from "strongly disagree" to "strongly agree." Self-rated overall health was assessed with a single item, with response options "excellent," "very good," "good," "fair," and "poor." Finally, patients who received the audio booklet were asked to rate its acceptability using questions previously used to assess audio booklets. ${ }^{21}$ Both patient and assessor knew if the patient received the standard reading materials or the audio booklet.

\section{Analysis}

Comparisons of patient characteristics between treatment groups were performed using two-sample $t$-tests for continuous variables and Pearson $\chi^{2}$ tests or Fisher's Exact tests for categorical variables for the African American and Hispanic ethnic groups separately. The groups were analyzed separately because they were markedly different in their baseline characteristics. Changes in statin knowledge score from pretest between treatments were analyzed using two-sample $t$-tests for each ethnicity group. Comparisons of the percentages of correct answer for each statin knowledge question between pretest and post-test were performed using McNemar's test by treatments and ethnic groups. All tests were two-sided. A $P$ value $\leq 0.05$ was considered to indicate statistical significance. All statistical analyses were performed with SAS software, version 9.1 (SAS Institute Inc, Cary, NC).

\section{Results}

\section{Sample characteristics}

Sixty-six African American and 66 Hispanic (Spanishspeaking) patients were randomized. Attrition was $4 \%$ and was solely due to patients needing to leave the assessments before completion. Characteristics of the patients in the study are given in Table 1. Among Hispanic patients, over $80 \%$ indicated Spanish as their primary language, over $80 \%$ had less than 12 years of education, and most were born outside of the US. Patients had been taking statins for an average of 2.8-4.3 years. Over half of the patients $(53.6 \%-66.7 \%)$ indicated that they took their statin medication every day in the past week, while others forgot to take their medication on at least one day. Over half of the patients $(53.6 \%-67.9 \%)$ indicated their overall health was fair to poor. Among African American patients, marital status differed between the groups; $9.7 \%$ assigned to the audio booklet intervention were currently married or living with a partner compared with $34.5 \%$ of patients assigned to the standard of care intervention. As expected, the majority of patients were of marginal or inadequate health literacy as measured by the Short Test of Functional Health Literacy in Adults.

\section{Acceptability of audio booklet}

Both African American and Hispanic patients rated the audio booklet favorably. All listened to the entire recording, and only three did not read along. Over $90 \%$ of patients reported the length of the audio booklet was about right (the remainder indicated the audio booklet was too short), the information was clear, they could relate to the stories, they believed the people, and felt the stories could happen to them. While over $90 \%$ of subjects indicated they liked using the audio booklet while at the clinic, over $80 \%$ had not received similar materials at a clinic in the past. There were some differences between the patient groups, ie, the Hispanic patients rated the booklet design and sound quality slightly higher than did the African American patients.

\section{Patient knowledge}

At the pretest, Hispanic patients who received the audio booklet had the lowest overall baseline knowledge scores (see Table 2). Significant improvement in knowledge of statins was observed for African American and Hispanic patients who received the audio booklet compared with those who received standard of care.

At the individual knowledge item level, African American and Hispanic patients assigned to the audio booklet improved their knowledge of mild muscle pain as a side effect of taking 
Table I Characteristics of the sample, stratified for African American and Hispanic patients

\begin{tabular}{|c|c|c|c|c|c|c|}
\hline & \multicolumn{3}{|c|}{ African American patients } & \multicolumn{3}{|c|}{ Hispanic patients } \\
\hline & $\begin{array}{l}\text { Audio booklet } \\
(n=3 I)\end{array}$ & $\begin{array}{l}\text { Standard of care } \\
(n=29)\end{array}$ & $P$ value & $\begin{array}{l}\text { Audio booklet } \\
(n=28)\end{array}$ & $\begin{array}{l}\text { Standard of care } \\
(n=28)\end{array}$ & $P$ value \\
\hline Age (mean [SD]) & $57.6(6.5)$ & $55.6(8.3)$ & 0.30 & $57.3(8.4)$ & $55.3(7.9)$ & 0.37 \\
\hline Female gender (n [\%]) & $20(64.5)$ & $20(69.0)$ & 0.71 & $19(67.9)$ & $20(7 \mathrm{I} .4)$ & 0.77 \\
\hline Education $<12$ years (n [\%]) & $7(22.6)$ & $8(27.6)$ & 0.65 & $23(82.1)$ & $23(82.1)$ & 1.00 \\
\hline Born in US ( $\mathrm{n}[\%])$ & $26(83.9)$ & $24(82.8)$ & 1.0 & $7(25.0)$ & $3(10.7)$ & 0.16 \\
\hline \multicolumn{7}{|l|}{ Marital status (n [\%]) } \\
\hline Divorced/Separated & II (35.5) & $5(17.2)$ & 0.02 & $4(14.3)$ & $3(10.7)$ & 0.41 \\
\hline Married/Living with partner & $3(9.7)$ & $10(34.5)$ & & $20(7 \mid .4)$ & $16(57.1)$ & \\
\hline Single & II (35.5) & $13(44.8)$ & & $3(10.7)$ & $5(17.9)$ & \\
\hline Widowed & $6(19.4)$ & I (3.5) & & $\mathrm{I}(3.6)$ & $4(14.3)$ & \\
\hline \multicolumn{7}{|l|}{ Functional health literacy $(\mathrm{n}[\%])^{*}$} \\
\hline Inadequate & $6(19.4)$ & $5(17.2)$ & 1.0 & $14(50.0)$ & II (39.3) & 0.37 \\
\hline Marginal & $20(64.5)$ & $20(69.0)$ & & II (39.3) & $10(35.7)$ & \\
\hline Adequate & $5(16.1)$ & $4(\mid 3.8)$ & & $3(10.7)$ & $7(25.0)$ & \\
\hline $\begin{array}{l}\text { Spanish language } \\
\text { administration (n [\%]) }\end{array}$ & N/A & $\mathrm{N} / \mathrm{A}$ & & $23(82.1)$ & 24 (85.7) & 1.0 \\
\hline
\end{tabular}

Notes: *Measured by the Short Test of Functional Health Literacy in Adults; $P$ values are from $t$-tests (for age) or $\chi^{2}$ tests or Fisher's Exact tests for categorical variables.

a statin. No improvements for this item were observed among patients assigned to standard of care. At the post-test, $64 \%$ of Hispanic and $86 \%$ of African American patients knew that they should not stop taking a statin after cholesterol levels improve.

Improvements in knowledge related to several areas of misinformation were also observed. Differences were observed for all patients regarding recognition that a skin rash was not a side effect of taking a statin, and African American patients who received the audio booklet showed a significant improvement regarding the recommendation to have liver enzymes checked by a doctor when taking a statin.

\section{Concepts from the Risk Behavioral Diagnosis Scale}

No differences from the pretest to post-test were observed for the measure of response efficacy, self-efficacy, personal susceptibility, and severity of the condition. There was a ceiling effect in that most mean scores at the pretest were above 6.0 on the seven-point scale.

\section{Discussion}

This feasibility study demonstrated that patients with low health literacy who have been prescribed a statin medication for hyperlipidemia could benefit from an educational intervention targeting their use of these medications. Patients who were provided with the booklet universally reported that they enjoyed the format, and found the information useful. African American patients had a fair level of knowledge about high cholesterol and statin therapy, while Hispanic patients in the intervention group had the lowest pre intervention knowledge. Regardless of their pre intervention knowledge, both groups in the intervention groups experienced a greater increase in knowledge about high cholesterol and statin therapy than their standard of care counterparts. Future studies will need to examine if this impacts patient adherence to statin regimes.

No other studies have examined the use of an audio booklet to improve statin knowledge. A study that examined the use of a tailored booklet about statin therapy was superior to a booklet about cholesterol in general. Patients who received

Table 2 Statin knowledge scores at pretest and post-test

\begin{tabular}{|c|c|c|c|c|c|}
\hline & $\mathbf{n}$ & $\begin{array}{l}\text { Pretest score } \\
\text { (mean [SD]) }\end{array}$ & $\begin{array}{l}\text { Post-test score } \\
\text { (mean [SD]) }\end{array}$ & Difference & $P$ value \\
\hline \multicolumn{6}{|c|}{ African American patients } \\
\hline Audio booklet & 31 & 8.39 [2.94] & $10.87[3.40]$ & $2.48[2.45]$ & $<0.01$ \\
\hline Standard of care & 29 & 7.97 [2.67] & $8.24[2.6 I]$ & $0.28[2.19]$ & \\
\hline \multicolumn{6}{|l|}{ Hispanic patients } \\
\hline Audio booklet & 28 & $4.82[3.87]$ & 6.21 [3.57] & 1.39 [2.78] & 0.03 \\
\hline Standard of care & 28 & $7.21[3.52]$ & $7.00[4.00]$ & $-0.21[2.64]$ & \\
\hline
\end{tabular}

Notes: Means are from sum of correct responses to 15 -item knowledge measure. $P$ values from $t$-test on difference scores. 
the booklet had more knowledge about statins and were less likely to report having missed a dose after three months of the intervention. ${ }^{22}$ Our study is different in that it can also be used with patients who cannot read at all. Additionally, our intervention was available in English and Spanish.

We further found that before the intervention patients already appreciated the severity of their condition and considered themselves susceptible to heart attack and stroke. They similarly reported high self-efficacy and response efficacy before the intervention. Effective health messaging may have a role in reinforcing already positive appraisals of treating high cholesterol with statins, but additional gains may not be realized given these high baseline values.

Given the problems associated with patient adherence to statin medication therapy, ${ }^{4,6,23}$ we need new interventions to assist clinicians in better educating patients as to the importance of staying on statin therapy even if they feel fine and their cholesterol levels normalize.

While statin therapy is important, clinicians are frequently pressed for time and do not think that they have enough time available to counsel patients appropriately. ${ }^{24,25}$ The problem is compounded by the fact that it is often difficult to gauge a patient's health literacy rapidly, so the patient education that a clinician does deliver may not be appropriately worded for the patient to comprehend well. ${ }^{18,26}$

Our intervention is unique in the fact that it is for low health literacy patients, but was designed in such a way that it delivers the content in a manner appropriate for any health literacy level. In addition, it does not rely on precious clinician-patient time to be delivered. The clinician supplies the audio booklet to the patient and is available for questions; however most of the educational burden is shifted off the clinician and onto the audio booklet. Moreover, the fact that it is available in both English and Spanish means that the tool is able to reach the majority of the US patient population.

The sequelae of disease related to hyperlipidemia are well documented and established. ${ }^{27}$ For appropriate patients, taking a statin medication can dramatically decrease their risk of stroke and/or heart attack. ${ }^{28}$ Future research needs to consider the impact of the intervention on subsequent adherence over a longer period of time. Three study subjects reported that they had stopped taking statins, but after the intervention they planned on resuming them. For these types of patients, and for those who are just starting statin therapy, the intervention needs to be tested to see if it actually improves their taking of their statin.

The main limitation of this study were that the patients were limited to one health care system. The results may not be generalizable to other patient populations. Additionally, increased knowledge about statin therapy may or may not influence patient adherence with the regime.

\section{Conclusion}

In this study of a novel audio booklet that educates patients about high cholesterol and statin therapy, the intervention was liked by patients and increased their knowledge about statin therapy. Future trials will need to evaluate the impact on patient behavior and the durability of effect. The intention behind the audio booklet was to relieve some of the counseling burden that physicians experience on a daily basis. We have demonstrated that the booklet can be integrated into practice with positive patient experiences and increases in knowledge and understanding of statins. A future version of the booklet will be available on the web as both an interactive version and a downloadable version (see http://www.chainonline.org).

\section{Acknowledgments}

This project was supported by grant U18-HS016093 from the Agency for Healthcare Research and Quality. We also thank Sonia Rodriguez and Donna Rochon for their assistance in managing the project and collecting the study data.

\section{Disclosure}

The authors report no conflicts of interest in this work.

\section{References}

1. Baigent C, Keech A, Kearney PM, et al. Efficacy and safety of cholesterol-lowering treatment: prospective meta-analysis of data from 90,056 participants in 14 randomised trials of statins. Lancet. 2005; 366(9493): 1267-1278.

2. Ose L, Davidson MH, Stein EA, et al. Lipid-altering efficacy and safety of simvastatin $80 \mathrm{mg} /$ day: long-term experience in a large group of patients with hypercholesterolemia. World Wide Expanded Dose Simvastatin Study Group. Clin Cardiol. 2000;23(1):39-46.

3. Avorn J, Monette J, Lacour A, et al. Persistence of use of lipidlowering medications: a cross-national study. JAMA. 1998;279(18): $1458-1462$.

4. Howell N, Trotter R, Mottram D, Rowe P. Compliance with statins in primary care. Pharm J. 2004;272:223-226.

5. Insull W. The problem of compliance to cholesterol altering therapy. J Intern Med. 1997;241(4):317-325.

6. Jackevicius CA, Mamdani M, Tu JV. Adherence with statin therapy in elderly patients with and without acute coronary syndromes. JAMA. 2002;288(4):462-467.

7. Mansur AP, Mattar AP, Tsubo CE, Simao DT, Yoshi FR, Daci K. Prescription and adherence to statins of patients with coronary artery disease and hypercholesterolemia. Arq Bras Cardiol. 2001;76(2):111-118.

8. Mantel-Teeuwisse AK, Goettsch WG, Klungel OH, de Boer A, Herings RM. Long term persistence with statin treatment in daily medical practice. Heart. 2004;90(9):1065-1066.

9. Tsuyuki RT, Bungard TJ. Poor adherence with hypolipidemic drugs: a lost opportunity. Pharmacotherapy. 2001;21(5):576-582. 
10. Kruse W, Weber E. Dynamics of drug regimen compliance - its assessment by microprocessor-based monitoring. Eur J Clin Pharmacol. 1990;38(6):561-565.

11. National Cholesterol Education Program (NCEP) Expert Panel on Detection, Evaluation, and Treatment of High Blood Cholesterol in Adults (Adult Treatment Panel III). Third Report of the National Cholesterol Education Program (NCEP) Expert Panel on Detection, Evaluation, and Treatment of High Blood Cholesterol in Adults (Adult Treatment Panel III) final report. Circulation. 2002;106(25):3143-3421.

12. Faulkner MA, Wadibia EC, Lucas BD, Hilleman DE. Impact of pharmacy counseling on compliance and effectiveness of combination lipid-lowering therapy in patients undergoing coronary artery revascularization: a randomized, controlled trial. Pharmacotherapy. 2000;20(4):410-416.

13. LaRosa JH, LaRosa JC. Enhancing drug compliance in lipid-lowering treatment. Arch Fam Med. 2000;9(10):1169-1175.

14. Pearson T, Kopin L. Bridging the treatment gap: improving compliance with lipid-modifying agents and therapeutic lifestyle changes. Prev Cardiol. 2003;6(4):204-211.

15. Nielson-Bohlman L, Panzer AM, Kindig DA. Health Literacy: A Prescription to End Confusion. Washington, DC: Institute of Medicine, The National Academies Press; 2004.

16. DeWalt DA, Pignone MP. Reading is fundamental: the relationship between literacy and health. Arch Intern Med. 2005;165(17): 1943-1944.

17. Kirsch I, Jungeblut A, Jenkins L, Kolstad A. Adult Literacy in America: A First Look at the Findings of the National Adult Literacy Survey. Washington, DC: National Center for Education Statistics, US Department of Education; 1993.

18. Wolf MS, Gazmararian JA, Baker DW. Health literacy and functional health status among older adults. Arch Intern Med. 2005;165(17): 1946-1952.
19. Witte K, Meyer G, Martell D. Effective Health Risk Messages: A Step-by-Step Guide. Thousand Oaks, CA: Sage Publications Inc; 2001.

20. Baker DW, Williams MV, Parker RM, Gazmararian JA, Nurss J. Development of a brief test to measure functional health literacy. Patient Educ Couns. 1999;38(1):33-42.

21. Volk RJ, Spann SJ, Cass AR, Hawley ST. Patient education for informed decision making about prostate cancer screening: a randomized controlled trial with 1-year follow-up. Ann Fam Med. 2003;1(1): 22-28.

22. Weymiller AJ, Montori VM, Jones LA, et al. Helping patients with type 2 diabetes mellitus make treatment decisions: statin choice randomized trial. Arch Intern Med. 2007;167(10):1076-1082.

23. Sobel RM, Paasche-Orlow MK, Waite KR, Rittner SS, Wilson EA, Wolf MS. Asthma 1-2-3: a low literacy multimedia tool to educate African American adults about asthma. J Community Health. 2009;34(4):321-327.

24. Ostbye T, Yarnall KS, Krause KM, Pollak KI, Gradison M, Michener JL. Is there time for management of patients with chronic diseases in primary care? Ann Fam Med. 2005;3(3):209-214.

25. Yarnall KS, Pollak KI, Ostbye T, Krause KM, Michener JL. Primary care: is there enough time for prevention? Am J Public Health. 2003; 93(4):635-641.

26. Institute of Medicine. Speaking of Health: Assessing Health Communication Strategies for Diverse Populations. Washington, DC: The National Academies Press; 2002.

27. Hingorani AD, Psaty BM. Primary prevention of cardiovascular disease: Time to get more or less personal? JAMA. 2009;302(19): 2144-2145.

28. Di Angelantonio E, Sarwar N, Perry P, et al. Major lipids, apolipoproteins, and risk of vascular disease. JAMA. 2009;302(18):1993-2000.
Patient Preference and Adherence

\section{Publish your work in this journal}

Patient Preference and Adherence is an international, peer-reviewed, open access journal focusing on the growing importance of patient preference and adherence throughout the therapeutic continuum. Patient satisfaction, acceptability, quality of life, compliance, persistence and their role in developing new therapeutic modalities and compounds to

\section{Dovepress}

optimize clinical outcomes for existing disease states are major areas of interest. This journal has been accepted for indexing on PubMed Central. The manuscript management system is completely online and includes a very quick and fair peer-review system. Visit http://www.dovepress.com/ testimonials.php to read real quotes from published authors. 